\title{
Impacts of fast food and the food retail environment on overweight and obesity in China: a multilevel latent class cluster approach
}

\author{
Xiaoyong Zhang ${ }^{1, *}$, Ivo van der Lans ${ }^{2}$ and Hans Dagevos ${ }^{1}$ \\ 'LEI, Wageningen University and Research Centre, PO Box 29703, 2502 LS The Hague, The Netherlands: \\ ${ }^{2}$ Marketing and Consumer Behaviour Group, Wageningen University and Research Centre, Wageningen, \\ The Netherlands
}

Submitted 1 October 2010: Accepted 7 July 2011: First published online 6 September 2011

\begin{abstract}
Objective: To simultaneously identify consumer segments based on individual-level consumption and community-level food retail environment data and to investigate whether the segments are associated with BMI and dietary knowledge in China.

Design: A multilevel latent class cluster model was applied to identify consumer segments based not only on their individual preferences for fast food, salty snack foods, and soft drinks and sugared fruit drinks, but also on the food retail environment at the community level.

Setting: The data came from the China Health and Nutrition Survey (CHNS) conducted in 2006 and two questionnaires for adults and communities were used. Subjects: A total sample of 9788 adults living in 218 communities participated in the CHNS.

Results: We successfully identified four consumer segments. These four segments were embedded in two types of food retail environment: the saturated food retail environment and the deprived food retail environment. A three-factor solution was found for consumers' dietary knowledge. The four consumer segments were highly associated with consumers' dietary knowledge and a number of sociodemographic variables.

Conclusions: The widespread discussion about the relationships between fastfood consumption and overweight/obesity is irrelevant for Chinese segments that do not have access to fast food. Factors that are most associated with segments with a higher BMI are consumers' (incorrect) dietary knowledge, the food retail environment and sociodemographics. The results provide valuable insight for policy interventions on reducing overweight/obesity in China. This study also indicates that despite the breathtaking changes in modern China, the impact of 'obesogenic' environments should not be assessed too strictly from a 'Western' perspective.
\end{abstract}

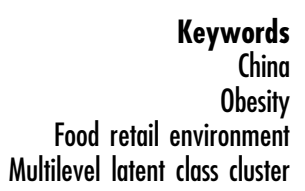

China

Obesity Multilevel latent class cluster
In recent years, growing scholarly attention ${ }^{(1-3)}$ has been paid to the relationships between food retail environments (e.g. access, availability and price) and obesity. Fast food is high in energy and low in micronutrient density, and fast-food consumption may contribute to the obesity epidemic ${ }^{(4-6)}$. Although research on the possible interactions between obesity and characteristics of the food environment is at an early stage and the evidence is currently too weak to draw firm conclusions ${ }^{(7)}$, US studies suggest that the food environment influences a healthy diet and obesity levels in North America ${ }^{(8-10)}$.

The clearly observable presence of processed foods, fast-food restaurants, supermarkets and other food outlets as factors determining the rising prevalence of overweight and obesity is a topic of research that is particularly relevant in the context of developed countries. Similar to the changing food retailing landscape in the postWorld War II era in Western countries ${ }^{(11,12)}$, the food retailing sector in China is experiencing dramatic changes half a century later. Over the past decade, supermarkets have been spreading faster in China than anywhere else in the world ${ }^{(13)}$. The impact of the food retail environment on consumers' dietary behaviour is a complex issue $^{(14)}$. Some researchers argue that supermarkets in developing countries typically provide cheap, processed and junk foodstuffs, which suggests that the growth of supermarkets is a driver of the transition towards diets high in energy and nutrient-poor foods ${ }^{(15,16)}$. Likewise, fast food is gaining popularity among younger generations and is widely spreading over both traditional and 
non-traditional food outlets ${ }^{(17,18)}$. Since entering China in the 1980s, the fast-food industry in China has attained an annual growth rate of $15 \%$. Despite a strand of research that documents the nutritional transition in China and its accompanying obesity epidemic ${ }^{(19-22)}$, few studies have explicitly focused on the relationships between obesity and the food environment in China ${ }^{(23)}$. The present paper investigates the relationships between consumers' fast-food preferences, the food retail environment and overweight and obesity in China in order to contribute to the relevant international debates on the issue of interactions between environmental factors and overweight/obesity.

The purpose of the study is threefold: (i) to identify segments of consumers on the basis of their fast-food preferences; (ii) to discover segments of the food retail environment and examine whether they are influencing consumers' preference patterns; and (iii) to examine whether fast-food preference patterns affect consumers' overweight and obesity as measured by BMI. At the end, consumers' demographic characteristics, including their nutritional knowledge, are used to profile the consumer patterns.

\section{Methods and procedures}

\section{Sample}

We utilized data from the China Health and Nutrition Survey (CHNS) ${ }^{(24)}$, which covers a sample of nine provinces in China. This Sino-US longitudinal survey has been widely used in China's dietary studies ${ }^{(19,25,26)}$. Since the first round of the survey in 1989, the questionnaire has been administered seven times, and approximately 4400 households (with a total of 19000 individuals) have participated. Further detailed information about this survey can be found at http://www.cpc.unc.edu/projects/china.

In the present study we used data from two questionnaires: the 2006 Adult Questionnaire and the 2006 Community Questionnaire. The 2006 Adult Questionnaire has been administered to a total sample of 9788 adults (age 18 years and older). The response rate in 2006 was $88 \%$, among the highest when compared with all other years. A total of 218 communities participated in the 2006 Community Questionnaire. Most community questions were directed to community heads and community accountants since they are the most informed resource people, while some were directed to local food safety inspectors.

\section{Measurements}

\section{BMI measurement}

BMI was calculated by dividing weight in kilograms by the square of height in metres. The measures of weight and height can be found in Dearth-Wesley et $a l^{(27)}$. We used the WHO-defined cut-off points to classify participants into four categories: underweight $\left(<18.5 \mathrm{~kg} / \mathrm{m}^{2}\right)$, normal weight $\left(18.5\right.$ to $\left.24.9 \mathrm{~kg} / \mathrm{m}^{2}\right)$, overweight $(25 \cdot 0$ to $\left.29 \cdot 9 \mathrm{~kg} / \mathrm{m}^{2}\right)$ and obesity $\left(\geq 30 \cdot 0 \mathrm{~kg} / \mathrm{m}^{2}\right)$.

\section{Fast-food preferences}

Food preferences were measured in the 2006 Adult Questionnaire by asking 'How much do you like this food?' in relation to five different food categories: (i) fast food (Kentucky Fried Chicken, pizza, hamburgers, etc.); (ii) salty snack foods (potato chips, pretzels, French fries, etc.); (iii) fruits; (iv) vegetables; and (v) soft drinks and sugared fruit drinks. Respondents were asked to choose one of the six answers: 1 = 'dislike very much'; 2 = 'dislike'; $3=$ 'neutral'; $4=$ 'like'; $5=$ 'like very much'; $9=$ 'do not eat this'. To simplify the data, we collapsed the six preference categories into four categories by merging 1 with 2 and 4 with 5 . As such, four categories remained: $1=$ 'dislike'; $2=$ 'neutral'; $3=$ 'like'; $9=$ 'do not eat this'.

\section{Food retail environment}

We utilized the number of food retailing businesses and the penetration of supermarkets in each community as indicators of the food retail environment. The question 'How many of these businesses are currently operating in this village/neighbourhood?' was directed to the community heads and community accountants in the 2006 Community Questionnaire. A total of ten types of food businesses were listed and presented. We took the sum of the ten types of food businesses in the community as an indicator of the density of the food business operation in the communities*. In addition, three questions were used to measure the penetration of supermarkets or hypermarkets in each community, namely the number of supermarkets within a $30 \mathrm{~min}$ bus ride from the community, the number of the floors as well as the total areas (square metres) of each supermarket.

\section{Dietary knowledge}

Consumers' dietary knowledge has been found to be an important predictor of healthy eating ${ }^{(28,29)}$. In the present study we investigated whether consumers' dietary knowledge is associated with their food preference patterns. The respondents were asked to provide their judgements on the health effects of twelve dietary knowledge statements. These statements were measured on a 5-point Likert scale from 'strongly disagree' to 'strongly agree'.

\section{Other factors}

Other factors used in the analysis include gender, age, region, education level and social status. Unfortunately, $88 \%$ of the respondents refused to reveal their income. Therefore, income was left out from the analysis.

We used primary occupation and the means of transportation to and from work or school as proxies for social status. The primary occupations were originally recorded

\footnotetext{
* In order to test the equality of such measurement, we ran a principal component analysis and extracted the first component as an index measuring the food environment. The correlation between this index and our sum score is as high as $0.995(P<0.001)$. These results give us confidence to use the simple sum as a measurement for the density of food business in each community.
} 


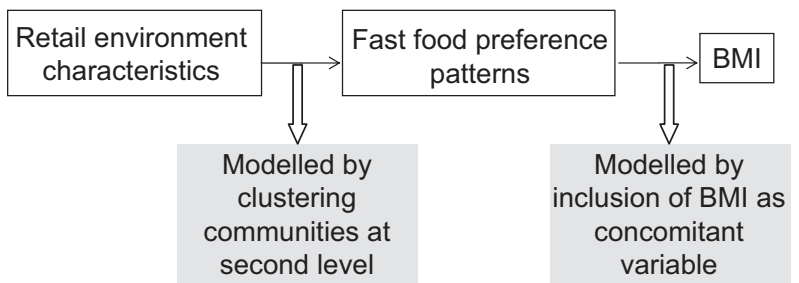

Fig. 1 The conceptual relationships of the modelling

in twelve categories. We merged them into three categories to illustrate status: manual worker (farmers, fisherman, etc.), service occupation (housekeeper, waiter, etc.) and professional work (doctor, midwife, etc.).

\section{Analysis}

Although an emerging field of research focuses on relationships between the food retail environment and individual health status and dietary intake, only a small number of studies have explicitly examined the multilevel structure of the data. These studies ${ }^{(8,30,31)}$ applied hierarchical linear modelling or logistic regression. In the current study, we take a latent class (LC) approach and simultaneously identify consumer segments at both the individual level and the food retail environmental level. Such models yield powerful methodological improvements over traditional approaches by recognizing existing market segments and thus providing insights into policy interventions on the basis of segmentation results.

The conceptual relationships of the modelling are presented in Fig. 1. First, we applied an LC cluster model ${ }^{(32)}$ on consumers' fast-food preferences. The goal of LC clustering is the same as other clustering techniques, i.e. to identify homogeneous groups. However, the LC cluster model has advantages over other, more traditional types of clustering techniques, such as the model selection criteria and probability-based classification ${ }^{(33)}$. In their comparative study, Magidson and Vermunt ${ }^{(34)}$ clearly demonstrate that LC clustering, which uses maximum likelihood as a criterion, is superior to traditional $K$-means clustering. Second, we included BMI as a concomitant variable in the same model to determine whether it is related to the fast-food preference segments.

Because our data have a multilevel character, with consumers within food retail environment in communities, we finally add a multilevel LC (MLLC) cluster model for the retail environmental data in addition to the standard LC cluster model. The MLLC cluster model takes a non-parametric random-coefficient approach, which allows the heterogeneity to be taken into account not only at the respondent level, but also at the community level ${ }^{(35)}$.

We used the computer program Latent GOLD 4.5 (Statistical Innovation Inc., Belmont, MA, USA) to fit both the simple LC cluster model and the MLLC cluster model. Furthermore, we applied principal component analysis for the twelve statements of dietary knowledge to identify
Table 1 Summary statistics for sample characteristics: adults ( $n$ 9788) living in 218 communities, China Health and Nutrition Survey, 2006

\begin{tabular}{|c|c|c|c|}
\hline Characteristic & Mean & SD & Valid cases* \\
\hline Age & $48 \cdot 84$ & $15 \cdot 35$ & 9788 \\
\hline \multirow[t]{2}{*}{$\mathrm{BMI}\left(\mathrm{kg} / \mathrm{m}^{2}\right)$} & $23 \cdot 42$ & $4 \cdot 30$ & 9180 \\
\hline & \multicolumn{2}{|c|}{$\%$} & \\
\hline \multicolumn{4}{|l|}{ Gender } \\
\hline Male & \multirow{2}{*}{\multicolumn{2}{|c|}{$\begin{array}{l}47 \cdot 6 \\
52 \cdot 4\end{array}$}} & 9788 \\
\hline Female & & & \\
\hline \multicolumn{4}{|l|}{ Education level } \\
\hline Primary school & \multicolumn{2}{|c|}{$25 \cdot 5$} & \multirow[t]{4}{*}{7315} \\
\hline Secondary school & & & \\
\hline High school \& technical degree & & & \\
\hline College and above & & & \\
\hline \multicolumn{4}{|l|}{ Region } \\
\hline Urban & & & \multirow[t]{2}{*}{9788} \\
\hline Rural & & & \\
\hline \multicolumn{4}{|l|}{ Primary occupation } \\
\hline Manual worker & & & \multirow[t]{3}{*}{5421} \\
\hline Service occupation & & & \\
\hline Professional occupation & & & \\
\hline \multicolumn{4}{|l|}{ Transportation meanst } \\
\hline Walk & & & \multirow[t]{4}{*}{5921} \\
\hline Bicycle & & & \\
\hline Bus/subway & & $\cdot 9$ & \\
\hline Car/taxi/motorcycle & & & \\
\hline
\end{tabular}

*Because of sometimes large numbers of missing data, the valid cases for each characteristic are presented.

†The four transport methods do not sum to $100 \%$ since participants were asked to answer 'Yes' or 'No' separately. The numbers shown in the table are 'Yes' answers.

the underlying factors. The resulting factor scores were used to profile the identified consumer clusters. The principal component analysis was performed using the SPSS statistical software package version $17 \cdot 0$ (SPSS Inc., Chicago, IL, USA).

\section{Results}

Summary statistics for the sample characteristics are presented in Table 1 . The sample consisted of 9788 respondents, with an average age of $48 \cdot 84$ years. The mean BMI was $23 \cdot 42 \mathrm{~kg} / \mathrm{m}^{2}$. Based on the WHO definition, approximately $23 \cdot 2 \%$ of the sample was overweight and the prevalence of obesity was $4.9 \%$.

Examining the food preference data, we found a high percentage of answers in the category 'like' for both fruits and vegetables (above 80\%), which implies that the preferences for these two food categories hardly differ between individual consumers. Therefore, we deleted the two food categories fruit and vegetables and included only the three fast-food items in the analysis.

A four-cluster solution was selected from our LC cluster analysis to identify segments with different fast-food preference patterns, since it had the lowest Bayesian information criterion (BIC; 56 086.94) compared with solutions with one, two, three and five clusters (see Appendix). Table 2 contains segment-specific proportions for the 
different fast-food preference categories in each of the four identified segments.

The first row of numbers in Table 2 shows the size of each segment, i.e. the prior probabilities. The cluster size shows that the first two clusters are dominant and account for $80 \%$ of the total sample. The last two clusters are rather small and make up the remainder $(20 \%)$ of the sample. When examining the segment-specific proportions, consumers in Cluster 1 had an extremely high chance (e.g. $98 \cdot 89 \%$ for fast food) of not eating products from any of the three food product categories. Thus, we

Table 2 Segment-specific proportions* for different fast-food preference categories in four consumer clusters ( $n$ 9140), China Health and Nutrition Survey, 2006

\begin{tabular}{|c|c|c|c|c|}
\hline & Cluster 1 & Cluster 2 & Cluster 3 & Cluster 4 \\
\hline Cluster size & 0.4558 & 0.3497 & $0 \cdot 1093$ & 0.0852 \\
\hline Cluster labels & 'Don't eat' & 'Dislike' & 'Neutral' & 'Like all' \\
\hline \multicolumn{5}{|c|}{ Fast food category } \\
\hline Dislike & 0.0059 & 0.8840 & 0.2119 & $0 \cdot 1977$ \\
\hline Neutral & 0.0032 & 0.0172 & 0.5752 & 0.0886 \\
\hline Like & 0.0020 & 0.0170 & 0.0351 & 0.5831 \\
\hline Don't eat & 0.9889 & 0.0819 & $0 \cdot 1777$ & 0.1306 \\
\hline \multicolumn{5}{|c|}{ Snack food category } \\
\hline Dislike & 0.0219 & 0.9328 & $0 \cdot 1690$ & 0.1126 \\
\hline Neutral & 0.0 & 264 & 80 & 0.0570 \\
\hline Like & 0.0253 & 0.0324 & 0.0507 & 0.7987 \\
\hline Don't eat & 0.9346 & 0.0084 & 0.0123 & 0.0317 \\
\hline \multicolumn{5}{|c|}{ Soft drinks category } \\
\hline Dislike & 0.1779 & 0.6664 & $0 \cdot 1866$ & 0.1899 \\
\hline Neutral & $0 \cdot 1584$ & $0 \cdot 1844$ & 0.5706 & $0 \cdot 1970$ \\
\hline Like & 0.0898 & 0.0999 & 0.2015 & 0.5857 \\
\hline Don't eat & 0.5739 & 0.0493 & 0.0413 & 0.0274 \\
\hline
\end{tabular}

${ }^{*}$ Bold font indicates the highest proportion per food category in each cluster.

Table 3 Segment-specific proportions of each BMl category in four consumer segments ( $n$ 9140), China Health and Nutrition Survey, 2006

\begin{tabular}{|c|c|c|c|c|}
\hline & Cluster 1 & Cluster 2 & Cluster 3 & Cluster 4 \\
\hline & 'Don't eat' & ‘Dislike' & 'Neutral' & 'Like all' \\
\hline Underweight & 0.0555 & 0.0466 & 0.0832 & 0.1199 \\
\hline Normal weight & 0.6502 & 0.6422 & 0.7164 & 0.6935 \\
\hline Overweight & 0.2385 & $0 \cdot 2554$ & $0 \cdot 1783$ & $0 \cdot 1667$ \\
\hline Obesity & 0.0558 & 0.0558 & 0.0221 & 0.0199 \\
\hline
\end{tabular}

labelled Cluster 1 as 'Don't eat' fast food. In Cluster 2, the category with the highest probability was 'Dislike' for all three products. Therefore, Cluster 2 was labelled as 'Dislike' fast food. Cluster 3 was called 'Neutral' since consumers in this cluster held a neutral position towards fast food, snack food and soft drinks. The last cluster was coined as 'Like all' since the highest probability for all three product categories was the indicator 'Like'. We also found that the segmentation was more dominated by the first two food categories, 'Fast food' and 'Snack food', and less dominated by the food product 'Soft drinks', since the latter's segment-specific proportions were more modest.

The results after including BMI as a concomitant variable are presented in Table 3, which provides segmentspecific proportions for each BMI category. The model with BMI as a concomitant variable performs much better in terms of BIC $(52684 \cdot 50)$ than the model without BMI. The model improvement is highly significant $(P<0 \cdot 001)$. The segment-specific proportions indicate the chances of each BMI category given one's cluster membership. By combining the probabilities of overweight and obesity for each cluster, we obtained the overweight/obesity rates of $29 \%, 30 \%, 20 \%$ and $18 \%$ for the four clusters, respectively. The results seem contrary to the common wisdom of the interaction of fast food and the rise of overweight/ obesity. Why do those who 'Dislike' (Cluster 2) and 'Don't eat' (Cluster 1) fast food, snack food and soft drinks have the highest overweight/obesity rate, while those who 'Like' (Cluster 4) and are 'Neutral' (Cluster 3) have the lowest? Bearing this question in mind, we searched for an answer from other perspectives such as the food retail environment and sociodemographics.

We began the MLLC cluster model with a one-group class model (assuming one segment at the community level), and then continued with two group classes and three group classes. The model with two group classes produced the lowest BIC (see Appendix), which was also lower than the BIC for the two previous models (Tables 2 and 3). Therefore, we identified an MLLC model with four consumer clusters embedded in two food retail environments.

The food retail environment characteristics of the two identified group classes can be further profiled (Table 4). Due to the count characteristics of the data, we tested

Table 4 Profiles of the two types of food retail environment ( $n$ 218), China Health and Nutrition Survey, 2006

\begin{tabular}{|c|c|c|c|}
\hline & Group 1 & Group 2 & \\
\hline Measures of food retail environment & $\begin{array}{l}\text { Saturated food retail } \\
\text { environment }\end{array}$ & $\begin{array}{l}\text { Deprived food retail } \\
\text { environment }\end{array}$ & $P$ value \\
\hline 1. Number of food businesses operating in this village/neighbourhood & $64 \cdot 53$ & $34 \cdot 88$ & $<0.001$ \\
\hline $\begin{array}{l}\text { 2. Number of supermarkets or hypermarkets within a } 30 \mathrm{~min} \text { bus ride from } \\
\text { this village/neighbourhood }\end{array}$ & 3.83 & $1 \cdot 47$ & $<0 \cdot 001$ \\
\hline $\begin{array}{l}\text { 3. Total number of floors of the supermarket/hypermarket to which most } \\
\text { residents in this village/neighbourhood go to shop }\end{array}$ & $3 \cdot 71$ & $2 \cdot 74$ & 0.779 \\
\hline $\begin{array}{l}\text { 4. Total area of all floors (square metres) of the supermarket/hypermarket } \\
\text { to which most residents in this village/neighbourhood go to shop }\end{array}$ & $3718 \cdot 83$ & $3088 \cdot 20$ & $<0 \cdot 001$ \\
\hline
\end{tabular}


the differences assuming a Poisson distribution. The last column provides the significance of the likelihood ratio $\chi^{2}$. The number of food businesses in Group Class 1 communities is significantly higher (with an average of sixtyfive businesses) than in Group Class 2 communities, which only have about half as many food businesses. In addition, the average number of supermarkets or hypermarkets within a $30 \mathrm{~min}$ bus ride from Group Class 1 communities was nearly four, while that in Group Class 2 communities was approximately $1 \cdot 5$, indicating a significantly different degree of supermarket penetration in the two groups of communities. There was also a significant difference for the average floor area of the supermarket/ hypermarket in which most residents in the community shop. The only non-significant measure is the average number of floors of the supermarket/hypermarket in which most residents shop. On the basis of these results, we named Group Class 1 the 'Saturated food retail environment' and Group Class 2 the 'Deprived food retail environment'.

Table 5 shows the results from the MLLC model, which contains the size of each group class and the probability of being in each cluster given one's communities group class. The estimated individual-level cluster probabilities of the food category preferences showed only small

Table 5 Proportions* of each cluster in the two food retail environments ( $n$ 218), China Health and Nutrition Survey, 2006

\begin{tabular}{lcc}
\hline & $\begin{array}{c}\text { Saturated food retail } \\
\text { environment }\end{array}$ & $\begin{array}{c}\text { Deprived food retail } \\
\text { environment }\end{array}$ \\
\hline $\begin{array}{l}\text { Group class size } \\
\text { Clusters }\end{array}$ & 0.5810 & 0.4190 \\
1. 'Don't eat' & 0.2500 & $\mathbf{0 . 7 4 1 2}$ \\
2. 'Dislike' & $\mathbf{0 . 4 7 6 3}$ & 0.1742 \\
3. 'Neutral' & 0.1550 & 0.0460 \\
4. 'Like all' & 0.1187 & 0.0386 \\
\hline
\end{tabular}

*Bold font indicates the highest proportion per food retail environment in each cluster. changes compared with the two previously presented models and are therefore not shown. Thus, these individuallevel clusters are basically the same as the previously identified individual-level clusters.

The multilevel model identified two group classes at the community's food environment level with a size of $58 \%$ and $42 \%$ each. The conditional probabilities revealed that the 'Saturated food retail environment' consisted of $25 \%$ of members of Cluster 1 ('Don't eat'), $48 \%$ of Cluster 2 ('Dislike'), $15 \%$ of Cluster 3 ('Neutral') and $12 \%$ of Cluster 4 ('Like all'). Cluster 1 ('Don't Eat') makes up $74 \%$ of the 'Deprived food retail environment', while Cluster 2 ('Dislike') makes up approximately half of the 'Saturated food retail environment'. Cluster 3 ('Neutral') and Cluster 4 ('Like all') have the highest chances of belonging to the 'Saturated food retail environment', although together they make up only about a quarter of it.

Having done the modelling work, we wished to start profiling consumers' preference patterns by their nutritional knowledge. We aimed to determine whether consumers' dietary knowledge can explain differences in overweight and obesity. Principal component analysis for the twelve dietary knowledge statements results in a threefactor solution (Kaiser-Meyer-Olkin index of sampling adequacy $=0.934$, total variance explained $=61.86 \%$ ).

The Varimax-rotated factor loadings are presented in Table 6. Items 4, 2, 3 and 6 loaded onto Factor 1. This factor therefore appears to reflect a type of health and dietary belief that favours high consumption of animal fats along with higher sugar and fats content in general. Thus, this factor was named as 'Pro fat and sugar diet'. Factor 2 was labelled as 'Pro bean and dairy diet' since items 9 and 8 loaded onto this factor. The final factor, Factor 3, was not in favour of sweaty sports but desired a heavy body. It reflected an outlook with no interest in athletics but favoured a full figure Therefore we chose the name 'Full-figure diet'. The mean factor scores for each

Table 6 Factor loadings* for three dimensions of dietary knowledge ( $n$ 9140), China Health and Nutrition Survey, 2006

\begin{tabular}{|c|c|c|c|}
\hline & Factor 1 & Factor 2 & Factor 3 \\
\hline Twelve statements & $\begin{array}{l}\text { Pro fat and } \\
\text { sugar diet }\end{array}$ & $\begin{array}{l}\text { Pro beans and } \\
\text { dairy diet }\end{array}$ & $\begin{array}{l}\text { Full-figure } \\
\text { diet }\end{array}$ \\
\hline 4. Choosing a diet high in fat is good for one's health & 0.755 & $0 \cdot 170$ & 0.257 \\
\hline 2. Eating a lot of sugar is good for one's health & 0.713 & $0 \cdot 240$ & 0.221 \\
\hline 3. Eating a variety of foods is good for one's health & 0.642 & 0.420 & 0.017 \\
\hline $\begin{array}{l}\text { 6. Consuming a lot of animal products daily (fish, poultry, eggs and lean meat) is } \\
\text { good for one's health }\end{array}$ & 0.621 & $0 \cdot 164$ & 0.393 \\
\hline 1. Choosing a diet with a lot of fresh fruits and vegetables is good for one's health & 0.579 & 0.378 & $0 \cdot 116$ \\
\hline $\begin{array}{l}\text { 5. Choosing a diet with a lot of staple foods (rice and rice products and wheat and } \\
\text { wheat products) is not good for one's health }\end{array}$ & 0.569 & $0 \cdot 051$ & 0.462 \\
\hline 7. Reducing the amount of fatty meat and animal fat in the diet is good for one's health & 0.501 & 0.299 & 0.388 \\
\hline 9. Consuming beans and bean products is good for one's health & $0 \cdot 246$ & 0.814 & 0.221 \\
\hline 8. Consuming milk and dairy products is good for one's health & $0 \cdot 260$ & 0.808 & $0 \cdot 182$ \\
\hline 10. Physical activities are good for one's health & 0.215 & 0.606 & 0.464 \\
\hline 11. Sweaty sports or other intense physical activities are not good for one's health & $0 \cdot 178$ & 0.231 & 0.824 \\
\hline 12. The heavier one's body is, the healthier he or she is & $0 \cdot 361$ & 0.325 & 0.558 \\
\hline
\end{tabular}

${ }^{*}$ Bold font indicates the higher factor loadings for each factor. 
Table 7 Profile of consumers in the four clusters, China Health and Nutrition Survey, 2006

\begin{tabular}{|c|c|c|c|c|c|}
\hline \multirow[b]{2}{*}{ Characteristic } & \multirow{2}{*}{$\frac{\text { Cluster } 1}{\text { 'Don't eat' }}$} & \multirow{2}{*}{$\frac{\text { Cluster } 2}{\text { 'Don't like' }}$} & \multirow{2}{*}{$\frac{\text { Cluster } 3}{\text { 'Neutral' }}$} & \multirow{2}{*}{$\frac{\text { Cluster } 4}{\text { 'Like all' }}$} & \multirow[b]{2}{*}{$P$ value* } \\
\hline & & & & & \\
\hline Age (mean) & $52 \cdot 2$ & $50 \cdot 1$ & $41 \cdot 9$ & $37 \cdot 3$ & $<0.001$ \\
\hline \multicolumn{6}{|l|}{ Gender (\%) } \\
\hline Male & $46 \cdot 9$ & $49 \cdot 0$ & $45 \cdot 3$ & $41 \cdot 2$ & \multirow[t]{2}{*}{$<0.001$} \\
\hline Female & $53 \cdot 1$ & $51 \cdot 0$ & $54 \cdot 7$ & $58 \cdot \overline{8}$ & \\
\hline \multicolumn{6}{|l|}{ Region (\%) } \\
\hline Urban & $25 \cdot 1$ & $43 \cdot 0$ & $42 \cdot 0$ & $36 \cdot 2$ & \multirow[t]{2}{*}{$<0.001$} \\
\hline Rural & $74 \cdot 9$ & $57 \cdot 0$ & $58 \cdot 0$ & $63 \cdot 8$ & \\
\hline \multicolumn{6}{|l|}{ Education (\%) } \\
\hline Primary school & $33 \cdot 1$ & $24 \cdot 0$ & $14 \cdot 4$ & $16 \cdot 4$ & \multirow{4}{*}{$<0.001$} \\
\hline Secondary school & $43 \cdot 2$ & $40 \cdot 8$ & $40 \cdot 0$ & $40 \cdot 4$ & \\
\hline High school \& technical degree & $18 \cdot 3$ & $24 \cdot 5$ & $33 \cdot 2$ & $26 \cdot 9$ & \\
\hline College \& above & $5 \cdot 4$ & $10 \cdot 6$ & $12 \cdot 5$ & $16 \cdot 4$ & \\
\hline \multicolumn{6}{|l|}{ Occupation (\%) } \\
\hline Manual work & $71 \cdot 6$ & $53 \cdot 3$ & $45 \cdot 1$ & $49 \cdot 6$ & \multirow{3}{*}{$<0.001$} \\
\hline Service occupation & $19 \cdot 9$ & $29 \cdot 6$ & $39 \cdot 0$ & $36 \cdot 0$ & \\
\hline Professional occupation & $8 \cdot 5$ & $17 \cdot 1$ & $15 \cdot 9$ & $14 \cdot 4$ & \\
\hline \multicolumn{6}{|l|}{ Transportation methods } \\
\hline Walk & $56 \cdot 7$ & $50 \cdot 5$ & $43 \cdot 8$ & $42 \cdot 5$ & $<0.001$ \\
\hline Bicycle & $23 \cdot 1$ & $21 \cdot 2$ & $21 \cdot 2$ & $24 \cdot 9$ & 0.376 \\
\hline Bus/subway & $3 \cdot 8$ & $6 \cdot \overline{5}$ & $9 \cdot \overline{6}$ & $15 \cdot 2$ & $<0.001$ \\
\hline Car/taxi/motorcycle & $10 \cdot 6$ & $15 \cdot 8$ & $17 \cdot 7$ & $16 \cdot 7$ & $<0.001$ \\
\hline \multicolumn{6}{|l|}{ Dietary knowledge (factor score) } \\
\hline Factor 1: Pro fat and sugar diet & $0 \cdot 13$ & $-0 \cdot 14$ & -0.07 & -0.06 & $<0.001$ \\
\hline Factor 2: Pro beans and dairy diet & 0.04 & -0.49 & -0.06 & -0.02 & $<0.001$ \\
\hline Factor 3: Full-figure diet & 0.13 & -0.96 & -0.09 & -0.09 & $<0.001$ \\
\hline Food retail environment & Deprived & Saturated & Saturated & Saturated & \\
\hline
\end{tabular}

${ }^{*}$ Of the $\chi^{2}$ value for testing independence in cross-tabulations for categorical characteristics and of the $F$ value for testing equality of means in ANOVA for metric characteristics.

cluster as well as the means and percentages of the sociodemographic characteristics for each cluster are presented in Table 7.

Table 7 shows that members in the 'Don't eat' cluster were likely to be the oldest ( 52 years old) among all four groups, with most of them living in the countryside. Compared with the other three clusters, they attained the lowest educational degree and their occupations were primarily manual work. They walked to and from work. Their dietary knowledge was unique. They considered that a diet containing high fat, more sugar and many animal products was good for their health, while intense physical activities were not good for their health. They perceived a heavy body as a healthy image. Members in this cluster lived in the second group of communities, 'Deprived food retail environment', where the number of food business operations and supermarkets was lower. We may conclude that the non-availability of fast food and snack food was the main reason for their 'Don't eat' behaviour.

Members in Cluster 2, 'Don't like', tended to be middleaged men living in the urban areas. They attained their middle-level school degree and performed manual work in the urban areas. Approximately half of them walked to work, but some utilized the bus and motorcycles. Their perception of dietary knowledge was opposite to that of Cluster 1 . They disagreed that sweaty sports are not good for one's health. They did not perceive that a heavy body is healthy, although they were quite heavy themselves. They did not consider fat and sugar, beans and dairy products as good for one's health. They seemed to dislike everything despite living in the saturated food business community.

Members in Cluster 3, 'Neutral', were typically middleaged women, primarily living in the urban areas. They received relatively higher education or technical degrees and engaged in service occupations. More than one quarter of them took a bus or a car to work. Although they lived in the 'Saturated food retail environment', they managed to obtain a relatively lower overweight and obesity rate.

Consumers in Cluster 4, 'Like all', had the lowest overweight and obesity rates. They represent the youngest urban women and had a relatively higher level of education. They lived in the 'Saturated food retail environment' and were employed in occupations such as service worker, office staff, as well as journalist professional workers. They had the highest percentages of taking a vehicle to work.

\section{Discussion}

Using an MLLC model, we have simultaneously identified four segments of consumers, namely 'Don't eat', 'Dislike', 'Neutral' and 'Like all', on the basis of fast food, snack food and soft drinks preferences. These four segments were embedded in two different food retail environments: saturated and deprived. Furthermore, we found that the two segments of consumers with high overweight and obesity 
rates were not unique in terms of fast food or snack preferences, but segmentation criteria were found in dietary knowledge, food retail environment and sociodemographics.

Our research reveals that the higher overweight and obesity rates from the 'Don't eat' segment were not related to fast food or snack food preferences since members in this segment did not have access to these products given the retail environment in which they resided. The main reasons for their heavy bodies may be explained by their dietary knowledge, which encourages them to eat more and become heavier. When considering the Chinese history in food security, this group suffered severely during the Great Chinese Famine in 1959-1961. Wang et al. ${ }^{(36)}$ also found an association between early nutritional status during the famine and the risk of overweight and obesity in Chongqing females in China. This disaster occurred mainly in the Chinese countryside and cost approximately 30 million Chinese lives. After such a catastrophe and following decades of chronic food shortage in the Chinese countryside, this group has a strong desire to devour more with the abundant supply of food today. Another point of worry with respect to this generation is that they have now entered into the role of grandparents. Grandparents provide the main childcare for the third generation in most of the countryside. Their ideas and thoughts may influence their grandchildren, which might create a new generation with limited dietary knowledge, accompanied by risks with regard to gaining weight and reaching BMI above $25 \mathrm{~kg} / \mathrm{m}^{2}$. For this group, their relatively low levels of nutritional knowledge about healthy food and food patterns is a more serious issue at present than the 'Westernization' of the food consumption environment in today's China. Public health for this segment is better served by paying attention to improve consumers' nutritional knowledge than to direct the attention to the food environment.

The other three segments all scored lower on the three factors of dietary knowledge, an indication of the opposite beliefs in comparison to Cluster 1. In particular, members in Cluster 2, 'Dislike', were strongly against the idea that intense physical exercise and a skinny body are unhealthy. This can be explained by a relatively large percentage of urban members in this cluster, who may have the desire of visiting a fitness centre and body building. The main reason for the high overweight and obesity rates in Cluster 2 may be explained by the relatively lower social status in the cities and the food retail environment. Consumers in Cluster 2 may perceive Western fast food as luxurious and expensive and thus 'Dislike' it because of its unaffordability. Alternatively, they purchase other local food products to satisfy their appetite since they live in a saturated food retail environment, where consumers have abundant access to both supermarkets and other food stores. The lower BMI in Cluster 3 ('Neutral') and Cluster 4 ('Like all') may be explained by their relatively higher social status as well as their proper dietary knowledge toward less sugar/fat and more physical exercise.
The research results generate important implications for policy interventions on preventing and reducing obesity in China. However, the target for the two higher BMI groups is quite different. For the 'Don't eat' segment, nutritional education and correct knowledge on a proper diet are urgently needed. Communication methods must be carefully designed since the individuals in this group are often scattered throughout the countryside and have the least education. Considering their nurturing roles for the third generation, schools should play an active role in providing students with information on healthy diets and preventing childhood obesity.

For the 'Don't like' segment, it is not useful to simply blame the saturated food environment. The rapid development of the retail industry, particularly supermarket development, is part of the agricultural structural transformation $^{(37)}$. The central issue that challenges policy makers is how to direct the food retail industry in such ways that it becomes part of the solution rather than part of the problem generated by an affluent diet and urban lifestyles.

With respect to the 'Neutral' and 'Like all' clusters, the interaction with the food environment is largely counterintuitive. In general, the present study shows that unlike the fast-changing 'Westernization' of China, it is too simplistic to study the Chinese obesity epidemic from a 'Western' perspective. As a consequence, it cannot be concluded that major changes in Westernized community food environments in many parts of today's China are causing higher levels of overweight and obesity at the consumer level. This underscores rather than diminishes the importance of and urgency for future research that focuses on understanding overweight and obesity among contemporary (Chinese) consumers in the context of (physical, social, informational and political) environmental factors, the so-called 'ecological approach'(38).

The methodological contribution of the present paper is that the MLLC cluster model succeeded in disentangling community-level effects from individual consumer-level effects. The identification of two classes at the community level indicated that individual consumers were not independent but nested in two different food retail environments.

We are aware that CHNS does not contain a nationally representative sample. Major cities such as Beijing and Shanghai were not included in the survey regions. Although these surveyed regions are experiencing the transitions of the retailing environment, the sample may still limit us from capturing the progressive nature of the most rapidly changing regions in China, where fast-food consumption is more prevalent. In addition, we used the number of food operating businesses as an indicator of the food retail environment in each community and ignored their type of operation and the types of food that they provide. Future obesity research should pay more attention to these front-running regions and to specific aspects of the changing food environments. 


\section{Acknowledgements}

This study was supported by the Wageningen University and Research Centre strategic research programme 'Plant and Animal for Human Health', which is funded by the Dutch Ministry of Agriculture, Nature and Food Quality. No conflict of interest was declared. X.Z. designed the study, analysed the data and drafted the manuscript. I.v.d.L. advised on the methodology and edited the manuscript. H.D. commented on and edited the manuscript.

\section{References}

1. Cummins S \& Macintyre S (2006) Food environments and obesity - neighbourhood or nation? Int J Epidemiol 35 , 100-104.

2. White M (2007) Food access and obesity. Obes Rev 8, Suppl. 1, 99-107.

3. Holsten JE (2008) Obesity and the community food environment: a systematic review. Public Health Nutr 12, 397-405.

4. Bowman S \& Vinyard B (2004) Fast food consumption of US adults: impact on energy and nutrition intake and overweight status. J Am Coll Nutr 23, 163-168.

5. Rosenheck R (2008) Fast food consumption and increased caloric intake: a systematic review of a trajectory towards weight gain and obesity risk. Obes Rev $9,535-547$.

6. Davis B \& Carpenter C (2009) Proximity of fast-food restaurants to schools and adolescent obesity. Am J Public Health 99, 505-510.

7. Schäfer-Elinder L \& Jansson M (2008) Obesogenic environments - aspects of measurement and indicators. Public Health Nutr 12, 307-315.

8. Diez-Roux A, Nieto F, Muntaner C et al. (1997) Neighborhood environments and coronary heart disease: a multilevel analysis. Am J Epidemiol 146, 48-63.

9. Ellaway A, Anderson A \& Macintyre S (1997) Does area of residence affect body size and shape? Int J Obes Relat Metab Disord 21, 304-308.

10. Moore L, Roux A, Nettleton J et al. (2009) Fast-food consumption, diet quality and neighbourhood exposure to fast food: the multi-ethnic study of atherosclerosis. $A m \mathrm{~J}$ Epidemiol 170, 29-36.

11. Tordjman A (1994) European retailing: convergences, differences and perspectives. Int J Retail Distrib Manage 22, 3-19.

12. Wrigley N (1998) How British retailers have shaped food choice. In The Nation's Diet: The Social Science of Food Choice, pp. 112-128 [A Murcott, editor]. New York: Addison Wesley Longman.

13. Hu D, Reardon T, Rozelle S et al. (2004) The emergence of supermarkets with Chinese characteristics: challenges and opportunities for China's agricultural development. Dev Policy Rev 22, 557-586.

14. Hawkes C (2008) Dietary implications of supermarket development: a global perspective. Dev Policy Rev 26, 657-692.

15. Asfauw A (2008) Does supermarket purchase affect the dietary practices of households? Some empirical evidence from Guatemala. Dev Policy Rev 26, 227-243.

16. Reardon T, Timmer P \& Berdegue J (2004) The rapid rise of supermarkets in developing countries: induced organizational, institutional, and technological change in agrifood systems. Electron J Agric Dev Econ 1, 168-183.
17. Creel J, Sharkey J, McIntosh A et al. (2008) Availability of healthier options in traditional and non-traditional rural fast-food outlets. BMC Public Health 8, 395.

18. Dave JM, An LC, Jeffrey RW et al. (2009) Relationship of attitudes toward fast food and frequency of fast-food intake in adults. Obesity (Silver Spring) 17, 1164-1170.

19. Dagevos H, He Y, Zhang X et al. (2011) Relationships among healthy lifestyle beliefs and body mass index in urban China. Int J Consum Stud 35, 10-16.

20. Zhang X, Dagevos H, He Y et al. (2008) Consumption and corpulence in China: a consumer segmentation study based on the food perspective. Food Policy 33, 37-47.

21. Zhai F, Wang H, Du S et al. (2010) Prospective study on nutrition transition in China. Nutr Rev 67, Suppl. 1, S56-S61.

22. Shankar B (2010) Socio-economic drivers of overnutrition in China. J Hum Nutr Diet 23, 471-479.

23. Li M, Dibley MJ, Sibbritt D et al. (2008) Factors associated with adolescents' overweight and obesity at community, school and household levels in Xián City, China: results of hierarchical analysis. Eur J Clin Nutr 62, 635-643.

24. Popkin B, Du S, Zhai F et al. (2010) Cohort profile: The China Health and Nutrition Survey - monitoring and understanding socio-economic and health change in China, 1989-2011. Int J Epidemiol 39, 1435-1440.

25. Bell A, Ge K \& Popkin B (2002) The road to obesity or the path to prevention: motorized transportation and obesity in China. Obes Res 10, 277-283.

26. Shankar B (2009) Obesity in China: the differential impacts of covariates along the BMI distribution. Obesity (Silver Spring) 18, 1660-1666.

27. Dearth-Wesley T, Wang H \& Popkin BM (2008) Under- and overnutrition dynamics in Chinese children and adults (1991-2004). Eur J Clin Nutr 62, 1302-1307.

28. Wardle J, Parmenter K \& Waller J (2000) Nutrition knowledge and food intake. Appetite 34, 269-275.

29. White M, Bunting J, Raybould S et al. (2004) Do Food Deserts Exist? A Multi-Level, Geographical Analysis of the Relationship between Retail Food Access, Socio-economic Position and Dietary Intake. Final Report to the Food Standards Agency, $U K$. Newcastle upon Tyne: Newcastle University.

30. Diez-Roux A, Nieto F, Caulfield L et al. (1999) Neighbourhood differences in diet: the Atherosclerosis Risk in Communities (ARIC) Study. J Epidemiol Community Health 53, 55-63.

31. Yen I \& Kaplan G (1999) Neighborhood social environment and risk of death: multilevel evidence from the Alameda County Study. Am J Epidemiol 149, 898-907.

32. Magidson J \& Vermunt JK (2004) Latent class models. In The Sage Handbook of Quantitative Methodology for the Social Sciences, pp. 175-198 [D Kaplan, editor]. Thousand Oaks, CA: Sage.

33. Vermunt JK \& Magidson J (2005) Technical Guide for Latent GOLD 4.O: Basic and Advanced. Belmont, MA: Statistical Innovations Inc.

34. Magidson J \& Vermunt JK (2002) Latent class models for clustering: a comparison with K-means. Can J Mark Res 20, $37-44$.

35. Vermunt JK (2003) Multilevel latent class models. Sociol Methodol 33, 213-239.

36. Wang Y, Wang X, Kong Y et al. (2009) The great Chinese famine leads to shorter and overweight females in Chongqing Chinese population after 50 years. Obesity (Silver Spring) 18, 588-592.

37. Timmer CP (2009) Do supermarkets change the food policy agenda? World Dev 37, 1812-1819.

38. Nayga RM (2008) Nutrition, obesity and health: policies and economic research challenges. Eur Rev Agric Econ 35, 281-302. 
Appendix 1

Latent class (LC) model results for fast-food preference*

\begin{tabular}{lcccc}
\hline Model & LL & BIC(LL) & Number of parameters & Classification error \\
\hline One cluster & -35353.67 & $70790 \cdot 00$ & 9 & 0.00 \\
Two clusters & $-29662 \cdot 17$ & 59498.83 & 19 & 0.02 \\
Three clusters & -28289.93 & $56846 \cdot 19$ & 29 & 0.05 \\
Four clusters & -27864.39 & 56086.94 & 39 & 0.06 \\
Five clusters & -27857.91 & $56165 \cdot 84$ & 49 & $0 \cdot 17$ \\
Four clusters + BMl covariate & -26123.36 & 52684.50 & 48 & 0.06 \\
\hline
\end{tabular}

LL, log likelihood; BIC, Bayesian information criterion.

*The value in bold denotes the lowest BIC value among alternative models.

\section{Appendix 2}

Multilevel latent class (MLLC) model results *

\begin{tabular}{lcccc}
\hline Model & LL & BIC(LL) & Number of parameters & Classification error \\
\hline Four-cluster with one G class & -26127.72 & 52638.50 & 42 & 0.05 \\
Four-cluster with two G classes & $-25232 \cdot 25$ & $\mathbf{5 0 9 1 1 . 4 1}$ & 49 & 0.05 \\
Four-cluster with three G classes & $-25330 \cdot 13$ & 51171.01 & 56 & 0.11 \\
\hline
\end{tabular}

LL, log likelihood; BIC, Bayesian information criterion.

${ }^{\star}$ The value in bold denotes the lowest BIC value among alternative models. 